Childhood injuries

\title{
Childhood injuries
}

\section{A A Hyder}

\section{A call for global attention}

lnom

njuries are currently a leading cause of death and disability in the world and account for more than five million deaths each year. ${ }^{1}$ A large majority of these deaths occur in low and middle income countries, where $90 \%$ of the world's population resides and where injury prevention is an emerging field. ${ }^{2}$ Globally, injuries (intentional and unintentional) are among the 10 leading causes of death and disease burden in the 0-4, 5-14, and 15-29 year age groups. Despite the magnitude of this burden, it is surprising to note the relative lack of global attention to childhood injuries in terms of both public policies and resource investments.

This issue of Injury Prevention plays its part in highlighting the importance of childhood injuries with the publication of three papers from two developed countries. The papers provide a valuable mix of both methodological and content information on specific types of unintentional childhood injuries with important lessons for prevention. Istre et al describe the ability of small area studies to answer specific questions about injury causation and the ability to inform appropriate actions for prevention. ${ }^{3}$ Exploring the causes of falls in 98 children in Dallas, USA lead them to define two structural hazards for children-distance between balcony rails and low positioned windows-for which environmental modifications are available. In addition, their study highlights the risk to younger ( $0-4$ years) children; the dangers of head injury from such falls with potential grave consequences; and the role of parental supervision in the causation of falls in younger children.

Another paper from the United States explores national data on a novel type of injury-washing machine related injuries in children. ${ }^{4}$ This study uses secondary analysis of a consumer commission electronic database to demonstrate the potential dangers with common household appliances, especially for very young (0-2 years) children. Older models of wringer machines, automatic washers, and babies being placed in car seats on machines were important risks for children. The latter is of great concern as it is reasonably common practice to recommend placing a "colicky" child in a car seat on top of washing machines and driers; this study shows the hazard in such advice and should be considered by clinicians.

In a paper from New Zealand, Simpson et al share results of a pilot study in which four methods were used to evaluate usage of child restraint devices for children (0-8 years)..$^{5}$ This paper demonstrates the utility of pilot studies to determine the most efficient method for obtaining specific types of information-including qualitative and quantitative methods. The ease of the simple observation method; the breadth of information derived from interviews combined with inspections; and the value of in-depth discussion in focus group sessions were all evident. In addition, it is clear that the strengths and weaknesses of each method identified in the paper are a mix of those generic to each method and some specific to the purpose of that study.

These three studies have implications for other parts of the world-beyond the United States and New Zealand. For example, there is an opportunity in the developing world to learn from the evolution of building codes and practices in the developed world to establish their own national standards which will protect children from falls. The dangers of household machines need to be highlighted in middle and upper class households in other parts of the world as increasing commercialization brings new appliances into their homes. Simple availability of interventions for childhood injuries in the developing world will not lead to their effective use; research to understand determinants of use (and non-use) will be critical to develop effective prevention programs.

These studies reiterate that despite progress in other areas of child health, injuries are a persisting condition in children all over the world. Experts in the field of pediatrics, child health, and adolescent care need to become strong advocates for addressing injuries globally. The International Society for Child and Adolescent Injury Prevention (ISCAIP) is one association created a decade ago by motivated professionals to address this important issue. ISCAIP has a dedicated membership interested in addressing childhood injuries through research, policy development, and implementation of programs. With 10 years of experience, ISCAIP intends to promote evidence based actions for the reduction of childhood injuries around the world. On the other hand $30 \%-50 \%$ of papers in Injury Prevention address childhood or adolescent injuries, directly or indirectly. It is thus an opportune time for a renewed collaboration between ISCAIP and the journal. Those publishing in this field should join colleagues in ISCAIP, and ISCAIP members should subscribe and promote the journal as a critical venue in the effort to reduce such injuries.

In recent years, the world has witnessed a slow but increasing interest in the global health community on other injury issues. The global campaign for landmines; the world campaign on violence; and road safety are all being addressed in some way. ${ }^{6}$ It is time for the global health community to recognize the toll of childhood injuries and make concerted efforts to reduce that burden.

Injury Prevention 2003;9:292

Correspondence to: Dr Adnan A Hyder, Department of International Health, Bloomberg School of Public Health, Johns Hopkins University, 615 North Wolfe Street, Suite E8132, Baltimore, MD 21205, USA; ahyder@jhsph.edu

\section{REFERENCES}

1 World Health Organization. World health report 2002. Geneva: WHO, 2002.

2 World Health Organization. Injury chart book Geneva: WHO, 2002.

3 Istre GR, McCoy MA, Stowe M, et al. Childhood injuries due to falls from apartment balconies and windows. Inj Prev 2003:9:349-52.

4 Warner BL, Kenney BD, Rice M. Washing machine related injuries in children: a continuing threat. Inj Prev 2003;9:357-60.

5 Simpson JC, Wren J, Chalmers DJ, et al. Examining child restraint use and barriers to their use: lessons from a pilot study. Inj Prev 2003;9:326-31.

6 World Health Organization. Available at: www.who.int/violence injury prevention (accessed on 15 September 2003) 